\title{
Anesthesia for Transoral Endoscopic Parathyroidectomy by Vestibular Approach (TOEPVA)
}

\author{
Fulya YILMAZ ${ }^{1}$ and Koray BAS ${ }^{1}$ \\ ${ }^{1}$ University of Health Sciences Izmir Bozyaka Education and Research Hospital
}

November 26, 2020

\begin{abstract}
Introduction: After thyroid diseases, hyperparathyroidism is one of the most common endocrine surgical disease. The increasing diagnosis of thyroid pathologies in early stages and a societal emphasis on physical appearances, especially in young women, have been led to development of new surgical techniques alternative to conventional transcervical incision consistently. Here, we describe our anaesthesia experience for parathyroidectomy with Transoral Endoscopic Parathyroidectomy by Vestibular Approach (TOEPVA). Material-method: Patients undergo TOEPVA at the Health Sciences University Izmir Bozyaka Training and Research Hospital between November 2018 and April 2019 were reviewed. Demographic data and hemodynamic parameters were reported. Seven patients were operated successfully by this technique none of which required conversion to conventional open surgery. Two patient required atropine and one patient required ephedrine during insufflation. Conclusion: After induction of anaesthesia with propofol, remifentanil and rocuronium; anaesthesia managed by desflurane co-administered with continous infusion of remifentanil, provide feasible and safe anaesthesia for TOEPVA. However, especially during hydrodissection and insufflation, a close cooperation between surgeon and anaesthetist have a great value to improve patient management.
\end{abstract}

\section{INTRODUCTION:}

After thyroid diseases, hyperparathyroidism is one of the most common endocrine surgical disease [1]. It occurs either from a disorder within the parathyroid glands (primary hyperparathyroidism) or disorder outside the parathyroid glands (secondary or tertiary hyperparathyroidism) [2]. In recent years, since described by Kocher in the late 1980's, treatment of hyperparathyroidism was the surgical removal of 4 parathyroid glands with transcervical incision [2-4]. After, realisation of that a single adenoma is the cause of hyperparathyroidism in most of the patients (80-85\%), surgical management was changed significantly [2]. With preoperative imaging tools (ultrasound and technetium-99m sestamibi scintigraphy) for localisation of the adenoma and intraoperative parathyroid hormone level measurements for confirmation, surgical excision of the offending parathyroid adenoma is still accepted as the main treatment of primary hyperparathyroidism $[1,2,5]$.

The increasing diagnosis of thyroid pathologies in early stages and a societal emphasis on physical appearances, especially in young women, have been led to development of new surgical techniques alternative to conventional transcervical incision consistently [3,6]. Over the last two decades, so many techniques such as Open Minimally Invasive Parathyroidectomies (OMIP), Minimally Invasive Video-Assisted Parathyroidectomy (MIVAP) and pure Endoscopic Minimally Invasive Parathyroidectomy (EMIP) and recently transoral endoscopic parathyroidectomy vestibular approach (TOEPVA) have been developed [3,7].

Here, we describe our anaesthesia experience for parathyroidectomy with Transoral Endoscopic Parathyroidectomy by Vestibular Approach (TOEPVA). According to our knowledge, this is the first report that explain anaesthesia management in TOEPVA. 
Methods: Seven patients undergo TOEPVA at the Health Sciences University Izmir Bozyaka Training and Research Hospital between November 2018 and April 2019. All patients were diagnosed with primary hyperparathyroidism due to a solitary parathyroid adenoma, and were managed by the same anaesthetist and by the same experienced surgeon on minimally invasive and endocrine surgery. Demographic data, drugs used for anesthesia management (induction, maintenance and extubation), hemodynamic parameters, end tidal carbondioxide and pulse-oximeter values, additional agents used preoperatively in anesthesia management and preoperative and peroperative measurements of PTH levels were recorded prospectively and evaluated retrospectively.

Preoperative setting: After informed consent of patient was approved for anaesthesia, all patients received preoperative anaesthesia evaluation, including laboratory tests and imaging studies (chest radiography, focused ultrasound for parathyroid adenoma mapping). Also preoperative PTH levels were obtained to compare intraoperative rapid parathormone levels. All patients received amoxicillin-clavulanic acid (1.2 gr) 30 minutes before the incision as antibiotic prophylaxis.

Anaesthesia management: After routine monitorization (Non-invasive blood pressure, electrocardiogram, end tidal carbondioxide and pulse-oximeter), anaesthesia was induced with propofol $(2 \mathrm{mg} / \mathrm{kg})$, remifentanil infusion $(0.01-0.5 \mathrm{mcgr} / \mathrm{kg} / \mathrm{min})$ and rocuronium $(0.6 \mathrm{mg} / \mathrm{kg})$ was administered to facilitate the tracheal intubation. Airway patency was achieved by nasal intubation with an inner diameter of $6.5 \mathrm{~mm}$ spiral endotracheal tube in six patients and with an inner diameter of $6.0 \mathrm{~mm}$ spiral endotracheal tube in one patient. Eyes were carefully closed to keep them closed peroperatively and to prevent contact with the solution (chlorhexidine and povidone iodine) used to clean the vestibular area. Dexametazone $(8 \mathrm{mg})$ and $\mathrm{H}_{2}$ blocker $(50 \mathrm{mg})$ were applied to all cases after anesthesia induction as routine clinical practice. Anaesthesia was maintained with desflurane $5 \%$ to $6 \%$ concentration in a gas mixture consisting of $45 \%$ oxygen in air. All patients were ventilated on

volume control ventilation mode with 5-7 mL / $\mathrm{kg}$ tidal volume and respiratory rate was modified to keep the end tidal carbondioxide within the normal values. Pulse-oximeter values were changed between 96$100 \%$ in all patients peroperatively. Neuromuscular blocker dose was repeated every 30 minutes routinely and also administered as rescue bolus dose if the view of surgical field was worsened. After removal of parathyroid adenoma, which was verified by histopathological examination and by blood PTH level decrease, we administered contramal as $0.3 \mathrm{mg} / \mathrm{kg}$ intravenously for postoperative analgesia. At the end of the operation, sugammadex $(2-4 \mathrm{mg} / \mathrm{kg})$ was administered to reverse the neuromuscular block. All patients transferred to Post Anaesthesia Care Unit (PACU) at the end of the operation and to their ward one hour after PACU stay, uneventfully.

Surgical management: All patients were operated by the same principles of TOEPVA which was described by Anuwong at al (8). In detail, the patient is placed in a supine position with slighlty neck extention. After a proper surgical preparation, a $10-11 \mathrm{~mm}$ transverse incision is made at the center of the oral vestibule just below the vermilion border. Once the periosteum is approached and identified by electrocautery and blunt dissection through the central incision the neck area is injected with 20 to $40 \mathrm{~mL}$ diluated epinephrine ( $0,5 \mathrm{mg}$ epinephrine in $500 \mathrm{~mL}$ saline) by a Veress needle. About $2,5 \mathrm{~cm}$ distance from this central incision two additional $5 \mathrm{~mm}$ vertical incisions are made on both sides, above and as lateral as possible to the canine teeth to avoid mental nerve injury. These lateral trocar sides are also prepared by injection with the same diluated epinephrine solution of 5 to $10 \mathrm{~mL}$. Then, one central $10-11 \mathrm{~mm}$ and two lateral $5 \mathrm{~mm}$ trocars are inserted and $\mathrm{CO}_{2}$ insufflation is began at a maximum pressure of $6 \mathrm{mmHg}$ with a flow rate of $6 \mathrm{~L} / \mathrm{min}$ to create an air pocket to perform parathyroidectomy with ordinary laparoscopic instruments.

Results: The patients characteristics, preoperative, operative and postoperative details are shown in Table 1. Two patients (Case 1 (Heart rate: $43 / \mathrm{min}$ ) and Case 5 (Heart rate: $41 / \mathrm{min}$ )) required atropine (0.5 $\mathrm{mg}$ ) and one patient (Case 2) (Blood pressure: $60 / 40 \mathrm{mmHg}$ ) required ephedrine (10 $\mathrm{mg}$ ) administration during insufflation. While all patients require lower dose remifenantil infusion during drapping and preparation for surgery after induction of anaesthesia; required higher doses remifentanil during hyrodissection. Except insufflation and hyrodissection phases of surgery, patients hemodynamic parameters were stable (changed 
$\pm 20 \%$ from baseline) during the operation time. Changes in mean arterial pressure and heart rate in cases by the operation time were shown on Figure 1 and Figure 2 respectively. No conversion to conventional open surgery was necessary. In all patients, intraoperative parathyroid hormone level decrease was confirmed by laboratory test.

\section{Discussion:}

Anuwong (8) introduced transoral endoscopic surgery using conventional laparoscopic instruments via oral vestibule, through premandibular space with $\mathrm{CO} 2$ insufflation. First they used this approach in thyroidectomy patients (Transoral endoscopic thyroidectomy by vestibular approach:TOETVA). They reported that, TOETVA is safe and feasible, resulting in no visible scar thus ideal method for cosmetic results. In 2016, Sasanakietkul T, Jitpratoom P and Anuwong A [2] adapted Anuwong's technique, which he introduced for TOETVA, to parathyroid surgery (primary hyperparatyrisidism or renal hyperparatyrisidism) using the inferior lip (Transoral endoscopic parathyroidectomy by vestibular approach:TOEPVA). They reported excellent cosmetic outcomes with feasible and safe surgical option.

While advances in surgical technique have been continued in parathyroid surgery, we have not been able to find recommendations regarding the anesthesia management of these cases in the literature. Up to date, there is no report is published about how we can manage these patients under general anaesthesia. Therefore, we want to share our anesthesia management in TOEPVA in the literature.

Transoral surgery can be considered as having three important stages in terms of anesthesia management. 1. Hydrodissection 2. Insufflations and 3. Surgical phase. While hydrodissection phase may cause an increase in sympathetic activity by diluated epinephrine solution used for hydrodissection; neck insufflations by carbon dioxide may cause sudden suppression of sympathetic activity. During the surgical phase, due to the surgical technique applied, absolute immobility of the case is very necesssary for anaesthetist and surgeon, to avoid serious events. The most important complications in surgical phase are pneumomediastinum and/or pneumothorax and recurrent laryngeal nerve injury which requires close capnography monitorisation and respiratuar follow-up respectively [9].

For the best management of all the phases that mentioned above, we preferred balanced anaesthesia (inhalation anaesthesia with opioid) in our anaesthesia management in TOEPVA. We preferred desflurane as inhalation anaesthetic; remientanil as opioid and rocuronium bromide as neuromuscular blocker. All patients were reversed by sugammadex and extubated at the end of the surgery. So in this article we want to explain why we preferred these agents in our anaesthesia management in TOEPVA.

Desflurane is a relatively new volatile anaesthetic, that have a low blood-gas solubility resulting in rapid uptake and elimination [10]. Its muscle-gas partition coefficient is lower than other volatile anaesthetics [11]. The enhancement of the neuromuscular blocking effects of muscle relaxants (both benzylisoquinoline and aminosteroid) by volatile anaesthetics is well known [11-13] and this phenomenon is called as "Potentiation" (10). Rocuronium bromide is a monoquaternary, aminosteroid, non-depolarising muscle relaxant with rapid onset and intermediate duration of action $[10,13]$. Sugammadex is a modified g-cylodextrin developed for reversal of neuromuscular blockade induced by aminosteroid neuromuscular blocking agents, particularly rocuronium by formatting a complex with rocuronium (encapsulation). Previous meta-analysis results reported that sugammadex is superior to neostigmine, as it reverses neuromuscular block faster and more reliable and accelerates postoperative discharge of patients after general anaesthesia [14,15].

Wulf and colleagues [10] reported that neuromuscular blocking effect of rocuronium to be enhanced by sevoflurane and desflurane, compared with total intravenous anesthesia (TIVA) (propofol/fentanil). Bock and et [12] showed that there was a marked interaction between neuromuscular blocking effects of rocuronium and isoflurane, desflurane and sevoflurane, compared with propofol. Maidatsi et al [11] reported that desflurane anaesthesia significantly prolongs the duration of action of rocuronium, compared to sevoflurane or propofol anaesthesia in anaesthesia maintainance regimens. Although in vitro studies propofol has been reported to potentiate the effects of neuromuscular blockers; there is no report to date that propofol can clinically potentiate the the effects of neuromuscular blockers clinically [13]. 
While neuromuscular blockade should be intense peroperatively because of the nature of the surgery; maintainance of the airway patency must be supplied at the end of the surgery. So we preferred rocuronium as a neuromuscular agent, which has a specific and reliable reversal agent to manage airway patency uneventfully after extubation and desflurane as an inhalation agent, which enhances the neuromuscular block effect of rocuronium peroperativelly.

It is important to measure intraoperative PTH level to verify the removal of pathological parathyroid adenoma. PTH has a short half-time and rapid metabolic clearance rate and has a rapid assay. But on the other hand, PTH level influenced by some many factors including stress, stress hormones (such as catecholamines, cortisol and inulin), general anesthesia and endotracheal intubation (the most stress-baring procedure), calcium, magnesium, vitamin $\mathrm{D}$, anesthetic agents (propofol) and laparoscopic surgeries (elevated blood $\mathrm{CO}_{2}$ may change blood $\mathrm{pH}$ and cause a shift of ionized calcium $[15,16]$. Also previous studies reported that propofol influence PTH level; Kivela et al results suggests that there is no need to avoid propofol during parathyroid surgery as previously suggested [16]. Whether propofol affects PTH level or not is still debate so we prefer inhalation anesthesia and desflurane as inhalation anaesthetic. We preferred propofol only during induction to prevent hemodynamic alternations to stress response and to suppress upper airway reflexes for nasal intubation.But Bacuzzi et al [9] suggest total intravenous anesthesia (bolus dose of propofol (2 mg/ $\mathrm{kg}$ ) followed by infusion $(0.2-0.5 \mathrm{\gamma} / \mathrm{kg} / \mathrm{min})$ of remifentanil) for transoral approaches.

Opioids have an important influence on upper airway events, purposeful movements during surgery and recovery time [18], the requirements for propofol or volatile anaesthetics $[18,19]$. Remifentanil has rapid onset, short duration of action [18-20], great intraoperative analgesia [19-21], quick recovery time [19-21], excellent controllability [18] and metabolized by non-spesific esterase so elimination is independent from liver and renal $[18,19]$. But over-administered opioid analgesics during surgery delay recovery from anaesthesia and cause opioid related side effects [19,20].

Ryu et al [20] compared intraoperative remifentanil requirements during equi-Minimum Alveolar Concentration (MAC) anesthesia of 1 MAC sevoflurane and desflurane anaesthesia via surgical pleth index-guided remifentanil administration. They reported that intraoperative remifentanil consumption was significantly lower in desflurane group than sevoflurane group. Kowark and colleagues [18] shown that in the presence of a continous infusion of remifentanil, desflurane is significantly superior than sevoflurane and propofol in terms of emergence from anaesthesia. Fukunaga et al [22] and Nooh et al [19] showed same results. Remifentanil provides effective suppression of cardiovascular responses to surgical stimulation and promotes hemodynamic stability and improves recovery profiles.

We preferred remifentanil infusion as opioid analgesic to manage sempatic activity changes during hydrodissection and insufflations phase of anaesthesia in our anaesthesia management because of its best pharmacokinetics and pharmacodynamics properties. And also we believe that we lower intraoperative remifentanil consumption, avoid over administered opioid side effects and better emergenced from anaesthesia as Kowark et reported ,by combining remifentanil with desflurane.

Some concerns exist regarding the safety of neck insufflations by carbon dioxide since then severe hypercapnia, acidosis, massive subcutaneous emphysema and tachycardia was observed [23,24]. Bellantone et al reported that carbon dioxide neck insufflations is safe [?]10 $\mathrm{mmHg}$ but use of insufflations pressures higher than $>15 \mathrm{mmHg}$ should be avoided to prevent metabolic and hemodynamic complications [24]. Rubino et al [23] reported that carbon dioxide neck insufflation up to $10 \mathrm{mmHg}$ does not alter intracranial pressure and is recommended for clinical application in endoscopic neck surgery. The important issues during neck insufflation are insufflation pressure and the rate of insufflation. The head and neck region is dense in terms of the vessel and nerve packs. Carbon dioxide neck insufflations may cause negative haemodynamic effects by compressing these packs. We must take care (atropine, ephedrine, adrenaline, large vessel, close communication with surgeon for urgent desufflation etc) during insufflation phase of surgery.

On the other hand, PTH itself causes alterations in vasodilatory properties of endothelium by hypercalcemia which leads to short QT intervals, prolongation of PR and QRS intervals and myocardial depression [25]. 
Therefore, we should follow ECG changes and hemodynamic parameteres more closely during anesthesia induction, hydrodissection and insufflation.

We does not prefer $\mathrm{N} 2 \mathrm{O}$ in laparoscopic surgeries in our clinical practice. In addition, $\mathrm{N} 2 \mathrm{O}$ increases postoperative nausea and vomiting $[9,21]$ which is a drug side effect that we do not want to encounter in patients with TOEPVA, not to met with any infection postoperatively.

Conclusion: This is the first study which describe the anesthetic management for TOEPVA in the literature. After induction of anaesthesia with propofol, remifentanil and rocuronium; anesthesia management by desflurane co-administered with continous infusion of remifentanil, provide feasible and safe anaesthesia for TOEPVA. However, especially during hydrodissection and insufflation, a close cooperation between surgeon and anaesthetist have a great value to improve patient management.Further studies are needed on anesthesia management for TOEPVA in clinical practice.

Conflict of interest/Funding disclosure statements

Fulya YILMAZ and Koray BAS have no conflicts of interest or financial ties to disclose.

\section{References:}

1. Bhargav PR, Sabaretnam M, Amar V, Devi NV. Applicability of transoral endoscopic parathyroidectomy through vestibular route for primary sporadic hyperparathyroidism: A South Indian experience. J Min Access Surg 2019;15:119-23

2. Sasanakietkul T, Jitpratoom P, Anuwong A. Transoral endoscopic parathyroidectomy vestibular approach: a novel scarless parathyroid surgery. Surg Endosc 2016:1-9

3. Russell JO, Clark J, Noureldine SI, Anuwong A, Khadem MGA, Kim HY, Dhillon VK, Dionigi G, Tufano RP, Richmon JD. Transoral thyroidectomy and parathyroidectomy- A North American series of robotic and endoscopic transoral approaches to the central neck. Oral Oncology 2017;71:75-80

4. Guerrero MA, Wray CJ, Kee SS, Frenzel JC, Perrier ND. Minimally Invasive Parathyroidectomy Complicated by Pneumothoraces: A Report of 4 Cases. Journal of Surgical Education 2007;64(2): 101-107

5. Sasanakietkul T, Carling T. Primary hyperparathyroidism treated by transoral endoscopic parathyroidectomy vestibular approach (TOEPVA). Surg Endosc. 2017;31(11):4832-4833

6. Razavi CR, Khadem MGA, Fondong A, et al. Early outcomes in transoral vestibular thyroidectomy: Robotic versus endoscopic techniques. Head \& Neck. 2018;00:1-8

7. Gagner M Rubino F. Endoscopic parathyroidectomy. In Endocrine surgery (eds) Schwartz AE, Pertsem-lidis D and Gagner M. Marcel Dek-ker: New York, 2004;289-296

8. Anuwong A. Transoral endoscopic thyroidectomy vestibular approach: a series of the first 60 human cases. World J Surg 2016;40:491-7

9. Bacuzzi A, Guzzetti L, Dionigi G, Menegaldo L, Alicino V, Zanghì GN, Freni F, Cuffari S. Anesthesiologist perspectives for the transoral approach. 2018;3(11):1-6

10. Wulf H, Ledowski T, Linstedt U, Proppc D, Sitzlack D. Neuromuscular ing effects um during isoflurane, blockof rocuronidesflurane, and sevoflurane anaesthesia. Can J Anaesth 1998;45(6):526-532

11. Maidatsi PG, Zaralidou AT, Gorgias NK, Amaniti EN, Karakoulas KA, Giala MM. Rocuronium duration of action under sevoflurane, desflurane or propofol anaesthesia. European Journal of Anaesthesiology 2004;21:781-786

12. Bock M, Klippel K, Nitsche B, Bach A, Martin E, Motsch J. Rocuronium potency and recovery characteristics during steadystate desflurane, sevoflurane, isoflurane or propofol anaesthesia. British Journal of Anaesthesia 2000;84 (1): 43-7

13. Lee S, Jin Ro Y, Uk Koh W, Nishiyama T, Yang HS. The neuromuscular effects of rocuronium under sevoflurane-remifentanil or propofolremifentanil anesthesia: a randomized clinical comparative study in an Asian population. BMC Anesthesiology 2016;16(65):1-7

14. Carron M, Zarantonello F, Tellaroli P, Ori C. Efficacy and safety of sugammadex compared to neostigmine for reversal of neuromuscular blockade: a meta-analysis of randomized controlled trials. Journal of Clinical Anesthesia 2016;35:1-12 
15. Carron M, Zarantonello F, Lazzarotto N, Tellaroli P, Ori C. Role of sugammadex in accelerating postoperative discharge: A meta-analysis. Journal of Clinical Anesthesia 2017;39:38-44

16. Cinamon U, Gavish D, SO, Goldfarb A, Ezri T. Effect of general anesthesia and intubation on parathyroid levels in normal patients and those with hyperparathyroidism. Head \& Neck. 2017;1-6

17. Kivela JE, Sprung J, Richards ML, Karon BS, Hofer RE, Liedl LM, Schroeder DR, Weingarten TN. Effects of propofol on intraoperative parathyroid hormone monitoring in patients with primary hyperparathyroidism undergoing parathyroidectomy: a randomized control trial. Can J Anesth 2011;58:525531

18. Kowark A, Rossaint R, Pu“hringer F, Keszei AP, Fritz H, Froba G, Rex C, Haas H, Otto V, Coburn $\mathrm{M}$, Study Collaborators. Emergence times and airway reactions during general anaesthesia with remifentanil and a laryngeal mask airway A multicentre randomised controlled trial. Eur J Anaesthesiol 2018; 35:588-597

19. Nooh N, Abdelhalim AA, Abdullah WA, Sheta SA. Effect of remifentanil on the hemodynamic responses and recovery profile of patients undergoing single jaw orthognathic surgery. Int. J. Oral Maxillofac. Surg. 2013; 42: 988-993

20. Ryu KH, Kim JA, Ko Dc, Lee SH, Choi WJ. Desflurane reduces intraoperative remifentanil requirements more than sevoflurane: comparison using surgical pleth index-guided analgesia. British Journal of Anaesthesia 2018:1-8

21. Grundmann U, Silomon M, Bach F, Becker S, Bauer M, Larsen B, Kleinschmidt S. Recovery profile and side effects of remifentanil-based anaesthesia with desflurane or propofol for laparoscopic cholecystectomy. Acta Anaesthesiol Scand 2001; 45: 320-326

22. Fukunaga AF, Alexander GE, Stark CW. Characterization of the analgesic actions of adenosine: comparison of adenosine and remifentanil infusionsin patients undergoing major surgical procedures. Pain 2003;101: 129-38

23. Rubino F, Pamoukian VN, Zhu JF, Deutsch H, Inabnet WB, Gagner M. Endoscopic endocrine neck surgery with carbon dioxide insufflation: The effect on intracranial pressure in a large animal model. Surgery 2000:1035-1041

24. Bellantone R, Lombardi CP, Rubino F, Perilli V, Sollazzi L, Mastroianni G, Gagner M. Arterial PCO2 and cardiovascular function during endoscopic neck surgerybwith carbondioxide insuflation. Arch surg 2001;136:822-827

25. Brown SJ, Ruppe MD, Tabatabai LS. The parathyroid gland and heart disease. MDCVJ 2017;13(2):4954

\section{Hosted file}

Figures.pdf available at https://authorea.com/users/379147/articles/495459-anesthesia-fortransoral-endoscopic-parathyroidectomy-by-vestibular-approach-toepva

\section{Hosted file}

Table 1.pdf available at https://authorea.com/users/379147/articles/495459-anesthesia-fortransoral-endoscopic-parathyroidectomy-by-vestibular-approach-toepva 